\title{
Effect of Organic Material Type and Proportion on the Physical and Mechanical Properties of Vegetation-Concrete
}

\author{
Daxiang Liu $\mathbb{D}^{1},{ }^{1}$ Baohua Zhang, ${ }^{1}$ Yueshu Yang $\left(\mathbb{D},{ }^{1}\right.$ Wennian Xu, ${ }^{2}$ Yu Ding, \\ and Zhenyao $\mathrm{Xia}^{3}$ \\ ${ }^{1}$ Key Laboratory of Geological Hazards on Three Gorges Reservoir Area, China Three Gorges University, \\ Ministry of Education, Yichang 443002, China \\ ${ }^{2}$ Key Laboratory of Disaster Prevention and Mitigation, China Three Gorges University, Hubei Province, Yichang 443002, China \\ ${ }^{3}$ Engineering Research Center of Eco-environment in Three Gorges Reservoir Region, China Three Gorges University, \\ Ministry of Education, Yichang 443002, China \\ Correspondence should be addressed to Yueshu Yang; 94273787@qq.com
}

Received 7 June 2018; Revised 11 September 2018; Accepted 18 September 2018; Published 2 December 2018

Academic Editor: Pietro Russo

Copyright (c) 2018 Daxiang Liu et al. This is an open access article distributed under the Creative Commons Attribution License, which permits unrestricted use, distribution, and reproduction in any medium, provided the original work is properly cited.

\begin{abstract}
Vegetation-concrete is one of the most widely used substrates in ecological slope protection engineering. The porosity of the vegetation-concrete must be high enough to satisfy the growth needs of the plant roots, while the mechanical properties must be strong enough to satisfy the self-stability requirement of the substrates on the slope. It is necessary to balance these two aspects in the design of vegetation-concrete. As one of the main components in vegetation-concrete, organic material has a remarkable effect on both the porosity and the mechanical properties of the substrate. In this paper, four types of common organic materials (rice husks, sawdust, and corn distillers' and unhulled rice distillers' grain) are chosen to research the effect of the organic material type and proportion on the porosity and mechanical properties of the substrate. The experimental results show that the porosity of samples containing corn distillers' grain is clearly higher than those of the other samples types, while situation of the mechanical properties is the opposite. It can be concluded that organic material with a large grain size is not suitable for use in vegetationconcrete directly and needs to be crushed before use to prevent crack formation. The research results also show that the rates of increase in porosity decrease with more organic material added, while the rates of decrease in the unconfined compressive strength and the elasticity modulus increase. From a comprehensive consideration of the required mechanical properties and plant growth, organic material with a small grain size is most suitable for use in vegetation-concrete, and the suitable proportion is between $7 \%$ and $9 \%$.
\end{abstract}

\section{Introduction}

Ecological restoration is an important aspect of environmental protection in zones disturbed by engineering. In terms of their topography, engineering-disturbed zones can be divided into two types: flat ground and slopes. Ecological restoration on flat ground is very easy to achieve, and the related theories and technologies are comparatively mature. However, the gradients of excavated slopes, waste disposal slopes, and hydrofluctuation belt slopes are usually very steep, and it is difficult to maintain the self-stability of soil and plants on such slopes. Therefore, ecological restoration on slopes has become a focus in the field of engineering. At present, several typical ecological restoration technologies involve spraying a thick layer of base material $[1,2]$; such methods include soil spraying $[3,4]$ and vegetation-concrete technology [5-7].

Vegetation-concrete, composed of soil, cement, organic material, seeds, and water in certain ratios, is particularly suitable for ecological restoration on slopes whose gradient is between $45^{\circ}$ and $85^{\circ}$. This technology has been applied along highways and around hydropower stations and mines, and the total application area has exceeded $2 \times 10^{6} \mathrm{~m}^{2}$ (Figure 1). However, continuous monitoring of the results of several restored slopes shows that most plant roots are distributed in only the surface layer of the vegetationconcrete. Clearly, this phenomenon is disadvantageous to the long-term stability of the plant community and is mainly 


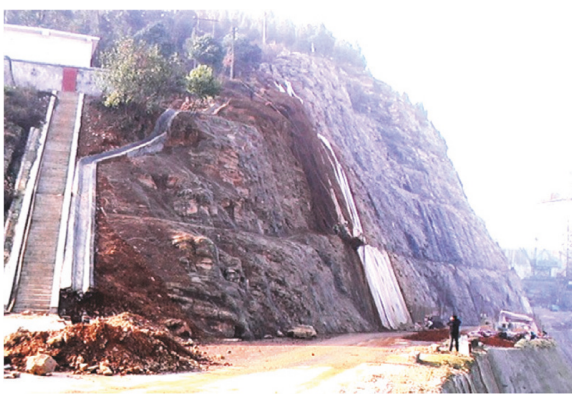

(a)

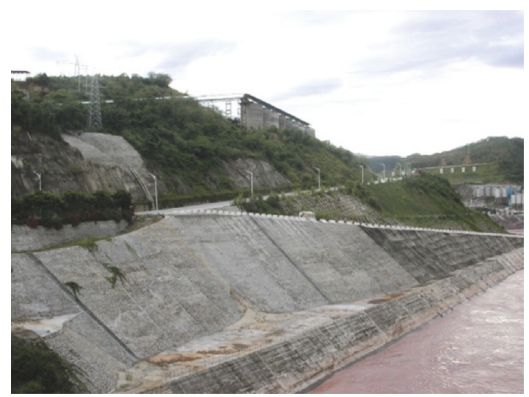

(c)

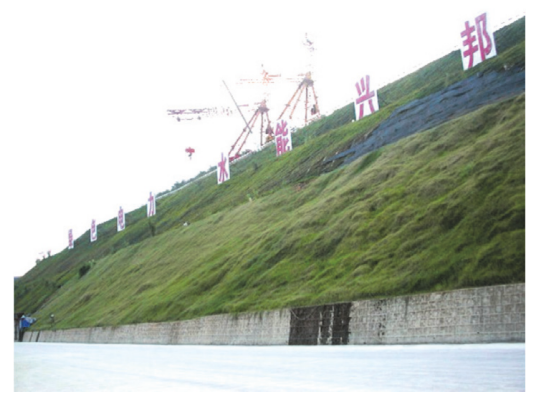

(e)

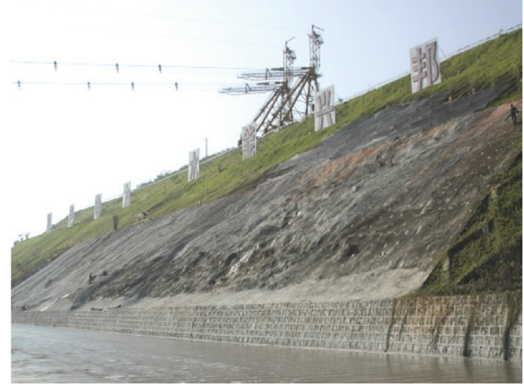

(b)

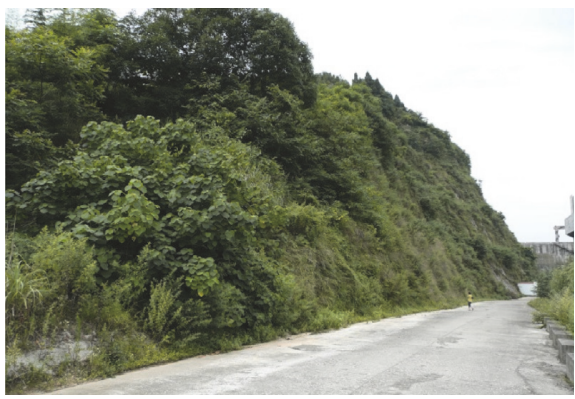

(d)

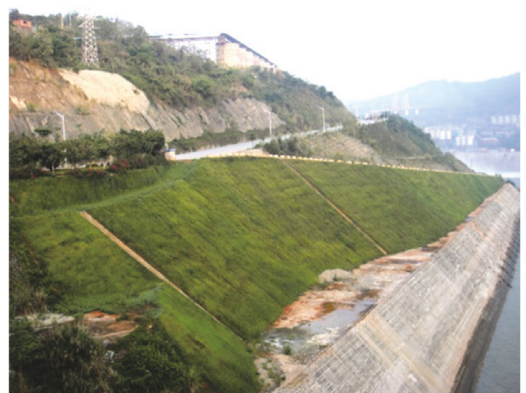

(f)

Figure 1: Typical vegetation-concrete ecological restoration engineering in China. (a, d) engineering locations at the Gaobazhou hydropower station in Hubei Province; (b, e) engineering locations at the Xiluodu hydropower station in Sichuan Province; (c, f) engineering locations at the Xiaowan hydropower station in Yunnan Province. (a) March 8th, 2008. (b) May 10th, 2011. (c) June 9th, 2012. (d) September 15th, 2013. (e) July 26th, 2014. (f) August 18th, 2014.

due to the low porosity of the vegetation-concrete. Organic material is a type of porous medium that is helpful for forming a cementing agent that can improve the soil texture; therefore, adding more organic material may be a useful method to improve the porosity $[8,9]$. Nevertheless, the proportion of organic material added to the concrete mix is inversely proportional to the resultant mechanical strength of the vegetation-concrete [10]. In this study, by researching the effect of different organic material types and proportions on the porosity and mechanical strength of vegetationconcrete, the most suitable type and proportion can be recommended.

\section{Materials and Methods}

2.1. Preparation of the Test Samples. In engineering applications, the raw materials of vegetation-concrete should be inexpensive and easily obtained. Thus, four types of common organic materials were chosen for the experiment: rice husks
$(\mathrm{RH})$, sawdust (SD), corn distillers' grain (CD), and unhulled rice distillers' grain (RD). To maintain the consistency of the water contents of the samples, all the organic materials were dried before the samples were fabricated.

The composition ratios of vegetation-concrete used in the experiment were as follows: the weights of the cement and water were $8 \%$ and $30 \%$ of that of the soil, respectively, and the tested design proportions of the organic material were $3 \%, 5 \%, 7 \%, 9 \%$, and $11 \%$, respectively. The characteristics of the materials were as follows. The soil was a type of yellow clay soil, and the dry density, natural water content, plastic limit, liquid limit, internal friction angle, and cohesion of this soil were $1.71 \mathrm{~g} / \mathrm{cm}^{3}, 25.3 \%, 22.5 \%, 40.4 \%, 14^{\circ}$, and $18 \mathrm{kPa}$, respectively. The cement was a type of ordinary Portland cement (P.O 32.5) produced by Yichang Huaxin Cement Co., Ltd. The RH was provided by the Weiming rice factory in the Xiling district of Yichang city, and the thicknesses of the husks were between 14 and $30 \mu \mathrm{m}$. The SD was provided by the Yemingzhu woodworking factory in the 
Yiling district of Yichang city, and the particle diameters were between 0.1 and $0.3 \mathrm{~mm}$. The CD and RD grains were both provided by Daohuaxiang Wine Co., Ltd. in Longquan town of Yichang city, and the grain diameters were between 0.3 and $0.5 \mathrm{~mm}$.

The dimensions of the samples used for the porosity tests were $70.7 \mathrm{~mm} \times 70.7 \mathrm{~mm} \times 70.7 \mathrm{~mm}$, while the dimensions of the samples used for the strength tests were $150 \mathrm{~mm} \times$ $150 \mathrm{~mm} \times 150 \mathrm{~mm}$ (Figure 2). The control standard of the sample quality was based on the density, and the samples whose density is between $1.55 \mathrm{~g} / \mathrm{cm}^{3}$ and $1.70 \mathrm{~g} / \mathrm{cm}^{3}$ satisfied the standard. Three samples were produced for each proportion of organic material tested. The samples were all placed into a standard curing room for 30 days at a temperature of $20^{\circ} \mathrm{C}$ and a relative humidity of $95 \%$ [11].

\subsection{Test Methods}

2.2.1. Porosity Test Method. In soil science, there is no clear classification of porosity type. However, porosity in concrete can be divided into two types: connected porosity and total porosity. Connected porosity is the ratio of the connected pore volume to the apparent volume of the soil, while total porosity is the ratio of the total volume of the connected and sealed pores to the apparent volume. Because cement is an important component of vegetation-concrete, it is necessary to distinguish between the two types of porosity. According to the method given by Yang et al. and Wang et al. [12-18], the total porosity $\left(P_{1}\right)$ can be calculated as follows:

$$
P_{1}=\left(1-\frac{W_{2}-W_{1}}{\rho_{\mathrm{w}} V}\right) \times 100 \%,
$$

where $W_{1}$ is the weight of the sample soaked in water for $24 \mathrm{~h}$ and measured in water (g); $W_{2}$ is the dry weight of the sample measured in air (g); $V$ is the apparent volume of the sample $\left(\mathrm{cm}^{3}\right)$; and $\rho_{\mathrm{w}}$ is the density of the water when the temperature is $4^{\circ} \mathrm{C}\left(\mathrm{g} / \mathrm{cm}^{3}\right)$.

The connected porosity $\left(P_{2}\right)$ can be calculated as follows:

$$
P_{2}=\left(1-\frac{W_{3}-W_{1}}{\rho_{\mathrm{w}} V}\right) \times 100 \%,
$$

where $W_{3}$ is the weight of the sample after curing for $24 \mathrm{~h}$ and measured in air $(\mathrm{g})$.

\subsubsection{Unconfined Compressive Strength Test Method.} Vegetation-concrete is very similar to the soil cement used widely in the field of civil engineering $[19,20]$. The major components of both materials are soil and cement, and the proportions of cement in soil cement and vegetationconcrete are also very similar. The mechanical properties of these two materials are closely related to the curing period, soil texture, and proportion of cement [21]. Consequently, it is reasonable to consult standards for soil or concrete testing when no direct relational standard or regulation for vegetation-concrete is available. Certain references on soil cement test methods suggest that using a universal testing machine to test the unconfined compressive strength of vegetation-concrete is feasible [22-26].

In this experiment, the pressurized equipment is a computer-controlled electrohydraulic servo universal testing machine produced by Jinan Shijin Co., Ltd. (model No. WAW-Y1000C). The loading mode is strain-controlled, and the loading rate is $1.2 \mathrm{~mm} / \mathrm{min}$.

\section{Results and Analysis}

3.1. Connected and Total Porosities. The calculation parameters and results for the connected and total porosities are shown in Table 1. According to formulas (1) and (2), the difference between the connected and total porosity $(\Delta P)$ can be calculated as follows:

$$
\Delta P=P_{1}-P_{2},
$$

where $\Delta P$ is the sealed porosity (\%).

Regarding the grain sizes of the organic materials used in the tests, the order is $\mathrm{CD}>\mathrm{RD}>\mathrm{RH}>\mathrm{SD}$. According to Table 1, it can be found that the samples containing SD and $\mathrm{CD}$ exhibit the maximum and the minimum $\overline{\Delta P}$, respectively. However, situation of $P_{2}$ is just the opposite. Therefore, the use of organic material with a small grain size is advantageous for the formation of sealed pores in vegetation-concrete, while organic material with a large grain size is much more beneficial for the formation of connected pores. In addition, the results in Table 1 also show that the main reason of total porosity increase is connected porosity increase with more organic material added. It can be deduced that the effect of the proportion of organic material is more obvious on connected pores than on sealed pores.

The curves of porosity with organic material proportion are shown in Figure 3. In general, the connected and total porosities of all the samples increase with increasing proportion of organic material. However, there are obvious differences between the curve change laws of the four types of samples. The rate of increase in the porosity of the samples containing $\mathrm{RH}$ decreases gradually with increasing proportion of organic material, while the rate of increase in samples containing CD remains almost stable. The curves of the samples containing $\mathrm{SD}$ or $\mathrm{RD}$ exhibit a stable stage when the proportion of organic material is between $7 \%$ and $9 \%$.

The pores in vegetation-concrete include interconnected and sealed pores. Because the roots of plants can cross not only connected pores but also sealed pores, total porosity plays an important role in the growth process of plants. Because the difference between connected and total porosity $\Delta P$ is a fixed value, the following analysis focuses mainly on total porosity.

In Figure 3, the curves of samples containing $\mathrm{CD}$ are always on the top, showing that $\mathrm{CD}$ has a more significant impact on porosity than the other types of organic materials added at the same proportions. Regarding the increasing trend of total porosity when the proportion increases from $3 \%$ to $11 \%$, the order is $\mathrm{RH}>\mathrm{RD}>\mathrm{SD}>\mathrm{CD}$. Although the total porosity of the sample containing $\mathrm{RH}$ is the lowest among the four types of samples when the proportion is $3 \%$, the rate of increase is highest. The change law of samples 


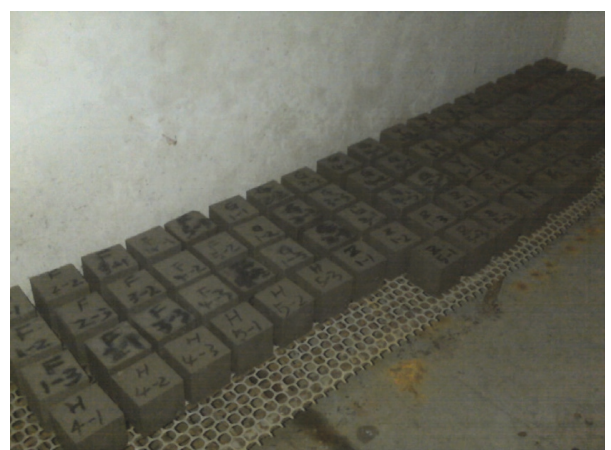

(a)

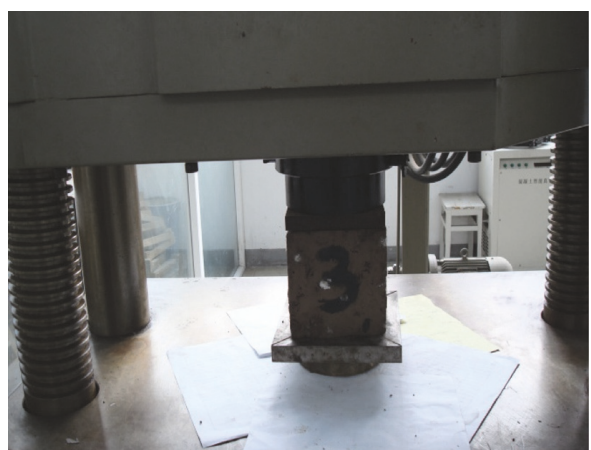

(b)

Figure 2: Dimensions of the experimental samples. (a) Dimensions: $70.7 \mathrm{~mm} \times 70.7 \mathrm{~mm} \times 70.7$. (b) $150 \mathrm{~mm} \times 150 \mathrm{~mm} \times 150 \mathrm{~mm}$.

TABLE 1: Calculation parameters and results for porosity (g).

\begin{tabular}{|c|c|c|c|c|c|c|c|c|}
\hline Type of organic material & Proportion (\%) & $W_{1}(\mathrm{~g})$ & $W_{2}(\mathrm{~g})$ & $W_{3}(\mathrm{~g})$ & $P_{1}(\%)$ & $P_{2}(\%)$ & $\Delta P(\%)$ & $\overline{\Delta P}(\%)$ \\
\hline \multirow{5}{*}{$\mathrm{RH}$} & 3 & 266.5 & 535.5 & 545.5 & 23.85 & 21.05 & 2.80 & \multirow{5}{*}{2.84} \\
\hline & 5 & 254.5 & 490.0 & 500.5 & 33.35 & 30.40 & 2.95 & \\
\hline & 7 & 259.0 & 472.0 & 482.0 & 39.70 & 36.90 & 2.80 & \\
\hline & 9 & 253.5 & 454.5 & 464.0 & 43.15 & 40.40 & 2.75 & \\
\hline & 11 & 220.5 & 411.0 & 421.0 & 45.85 & 42.95 & 2.90 & \\
\hline \multirow{5}{*}{ SD } & 3 & 267.5 & 525.0 & 537.0 & 27.10 & 23.70 & 3.40 & \multirow{5}{*}{3.43} \\
\hline & 5 & 254.5 & 485.0 & 497.0 & 34.80 & 31.40 & 3.40 & \\
\hline & 7 & 256.5 & 470.0 & 482.0 & 39.55 & 36.15 & 3.40 & \\
\hline & 9 & 236.0 & 447.5 & 459.5 & 40.15 & 36.75 & 3.40 & \\
\hline & 11 & 214.5 & 413.0 & 425.5 & 43.85 & 40.30 & 3.55 & \\
\hline \multirow{5}{*}{ CD } & 3 & 298.5 & 524.0 & 534.0 & 36.15 & 33.35 & 2.80 & \multirow{5}{*}{2.24} \\
\hline & 5 & 289.0 & 502.5 & 512.5 & 39.55 & 36.75 & 2.80 & \\
\hline & 7 & 278.0 & 483.5 & 494.0 & 41.85 & 38.90 & 2.95 & \\
\hline & 9 & 268.5 & 464.0 & 477.0 & 44.65 & 41.00 & $3.65^{*}$ & \\
\hline & 11 & 259.0 & 448.0 & 457.5 & 46.50 & 43.85 & 2.65 & \\
\hline \multirow{5}{*}{$\mathrm{RD}$} & 3 & 270.5 & 535.0 & 545.0 & 25.15 & 22.35 & 2.80 & \multirow{5}{*}{2.91} \\
\hline & 5 & 261.5 & 489.5 & 500.0 & 35.50 & 32.50 & 3.00 & \\
\hline & 7 & 251.5 & 463.5 & 474.0 & 40.00 & 37.05 & 2.95 & \\
\hline & 9 & 244.5 & 453.0 & 463.0 & 41.00 & 38.20 & 2.80 & \\
\hline & 11 & 224.5 & 420.5 & 431.0 & 44.55 & 41.55 & 3.00 & \\
\hline
\end{tabular}

*Abnormal data.

containing $\mathrm{CD}$ is the opposite: the porosity is the highest at first, but the rate of increase is the lowest. In addition, the porosity variance of the four types of samples is clearly considerable when the organic material proportion is $3 \%$, but the variance decreases when the proportion reaches $11 \%$.

The results can be divided into four stages with an increasing proportion of organic material. The rates of the increase in porosity for all samples during the first stage are greater than those during the other three stages; the rates of increase decrease as the proportion increases. It can be deduced that the impact of the organic material on the porosity is greater when less organic material is added.

3.2. Characteristics of the Stress-Strain Curve. The stressstrain curves for an organic material proportion of $9 \%$ are chosen for analysis. In Figure 4, the curves in each graph correspond to the three identical samples tested for each experimental condition. The curves for the samples containing $\mathrm{CD}$ are the least smooth. The main reason for this may be that the degree of expansion of CD is high when water is encountered, and microcracks gradually appear and grow inside the samples under a high-humidity curing environment. In addition, the strain of samples containing $\mathrm{CD}$ is very small when the stress is between 0 and $18 \mathrm{kPa}$, suggesting that samples that containing $C D$ possess the characteristics of brittle deformation [27]. This may be mainly because the grain size of CD is large and the interface contact area between the organic material and soil is small, which are disadvantageous to the interface binding property. Then, brittle deformation would occur if samples could not rely on the interface contact deformation to bear stress [28].

Similar to soil cement, vegetation-concrete possesses characteristics of both a hard brittle material and plastic material. By calculating the average value of the three samples for each test, the stress-strain curves of all the samples can be obtained (Figure 5). Each curve can be divided into 5 basic stages: (1) stage I is an automatic adjustment stage because the sample surface is not flat and is not in complete contact with the loading device; (2) stage II 


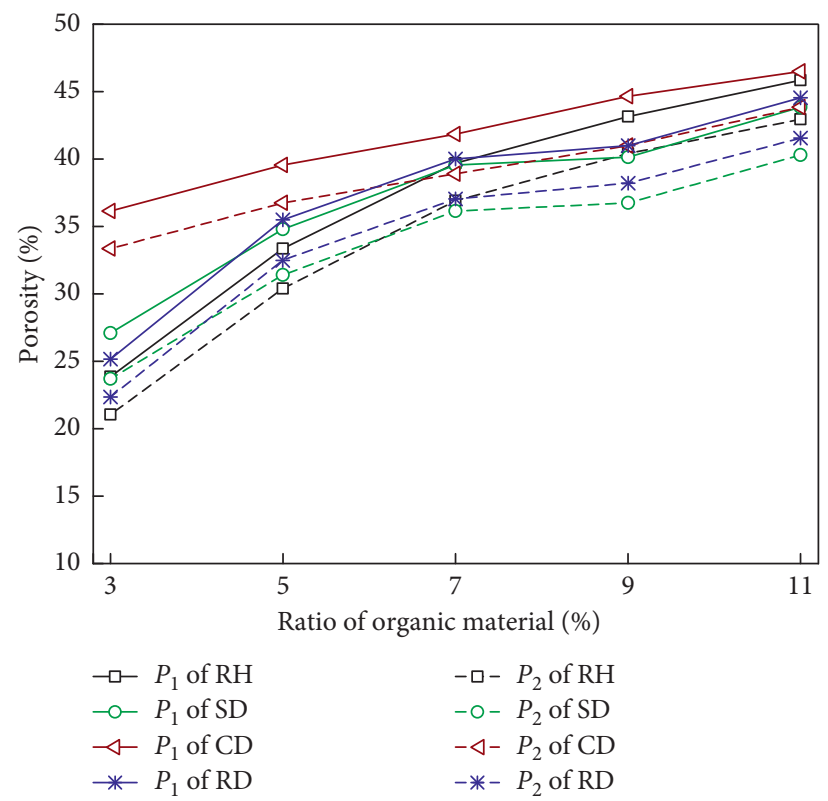

FIgURE 3: Curves of porosity against organic material ratio.

is the elastic deformation stage, when the stress is between $30 \%$ and $70 \%$ of the peak value, and is accompanied by slight plastic deformation due to the formation of a few microcracks caused by tensile stress in the samples; (3) stage III is a plastic deformation stage, when the stress is between $70 \%$ and $90 \%$ of the peak value; (4) at stage IV, the size and depth of the cracks increase rapidly as soon as the stress reaches the peak value; and (5) in stage $\mathrm{V}$, the strain continues to increase, and the sample can rely on only the friction force among the fragments created by cracks to bear the stress.

In Figure 5, the peak stresses of all the samples clearly decrease with an increasing proportion of organic material, and the times at which the peak stresses are achieved are also postponed. It can also be found that the curves of samples containing SD are more closely spaced than those of other samples, and the corresponding peak stresses are also the greatest. Therefore, the change in the proportion of SD has the lowest negative impact on the mechanical properties of the vegetation-concrete among the four types of organic material. In addition, with regard to the maximum strain, the samples containing SD all have strains greater than $27 \times$ $10^{-3}$, while other samples exhibits strains of only approximately $25 \times 10^{-3}$. Therefore, the deformation adaptability of samples containing SD is better than those of samples containing other organic material types [29].

\subsection{Unconfined Compressive Strength and Elasticity Modulus.} By extracting the data shown in Figure 5, the peak stress of all samples can be obtained. In Table 2, the unconfined compressive strength of samples containing CD is obviously lower than those of the other samples tested, which is also due to the microcracks caused by the expansion of the CD. With an increase in the proportion of organic material, the unconfined compressive strengths of all the samples decrease, and the rate of decrease as the proportion increases from $3 \%$ to $5 \%$ is lower than those during other stages, indicating that the impact of the proportion of organic material on the unconfined compressive strength is small when the proportion is low. In addition, the strength ratios $\left(q_{11 \%} / q_{3 \%}\right)$ of the four types of samples are 0.575 , $0.616,0.645$, and 0.592 , where $q_{3 \%}$ and $q_{11 \%}$ are the unconfined compressive strengths when the organic material proportions are $3 \%$ and $11 \%$, respectively. In other words, the order of the rate of decrease in the unconfined compressive strength is $\mathrm{RH}>$ $\mathrm{RD}>\mathrm{SD}>\mathrm{CD}$. Notably, the unconfined compressive strength of the sample containing SD is still greater than $0.3 \mathrm{MPa}$ when the organic material proportion is $11 \%$.

The elasticity modulus can also be extracted, as shown in Table 3 and Figure 5. The change law of the elasticity modulus is similar to that of the unconfined compressive strength, and it can be proven that the nondeformability of samples containing SD is the highest. The modulus ratios $\left(E_{11 \%} / E_{3 \%}\right)$ of the four types of samples are $0.444,0.494$, 0.400 , and 0.429 , where $E_{3 \%}$ and $E_{11 \%}$ are the elasticity moduli when the organic material proportions are $3 \%$ and $11 \%$, respectively. In other words, the impact of the proportion of SD on the elasticity modulus is the lowest among the results of the four types of organic materials.

\section{Suitable Type and Proportion of Organic Material Used in Vegetation-Concrete}

According to the research findings of Zheng et al. [30], the three-phase distribution of soil that is suitable for plant growth is as follows: the volumes of the solid material, water, and air are approximately $50 \%, 25 \%$, and $25 \%$ of the total soil volume, respectively; and the weights of the mineral substances and organic matter are approximately $95 \%$ and $5 \%$ of that of the solid material, respectively. However, Zhou and Zhang insisted that plants can still grow effectively even if the three-phase distribution of the ecological base material is not up to the above standard [31]. In this paper, it is found that porosity has an inverse relationship with unconfined 

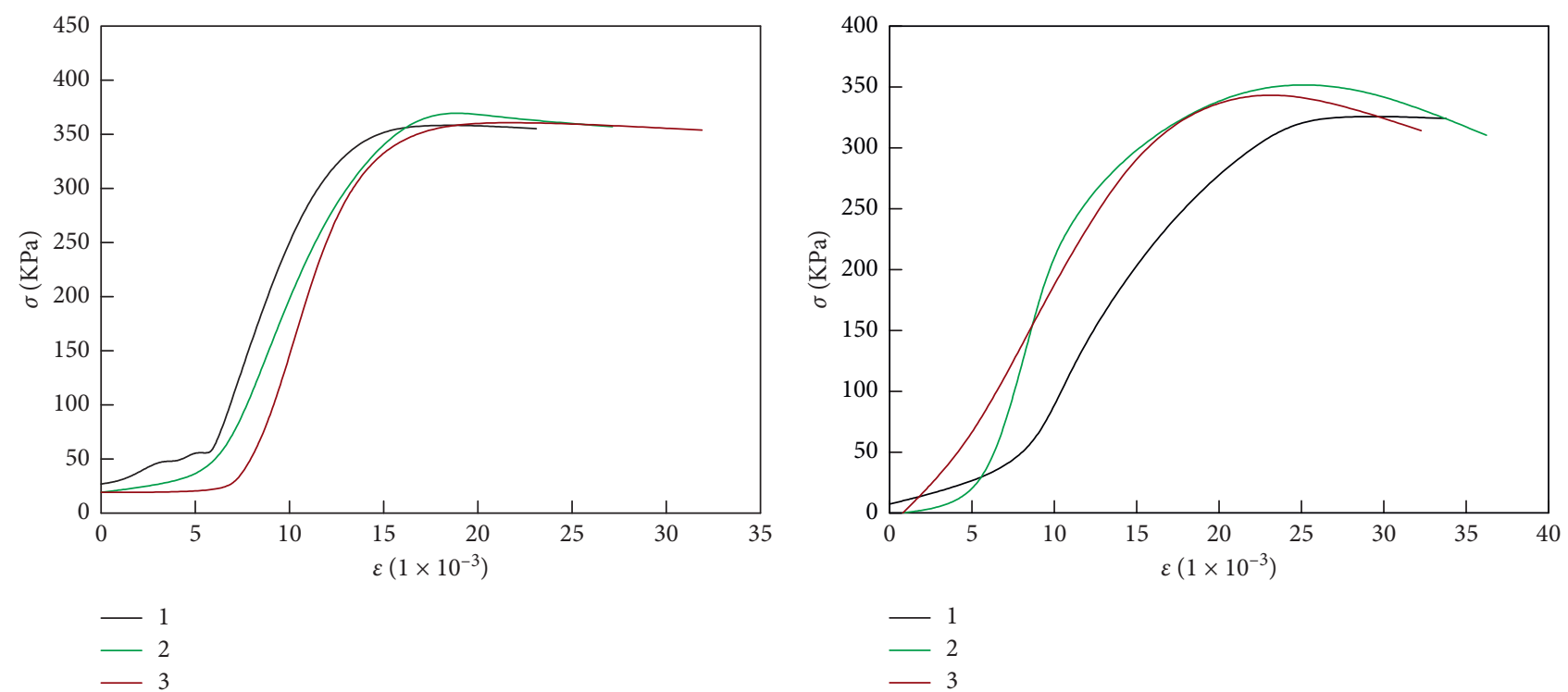

(a)
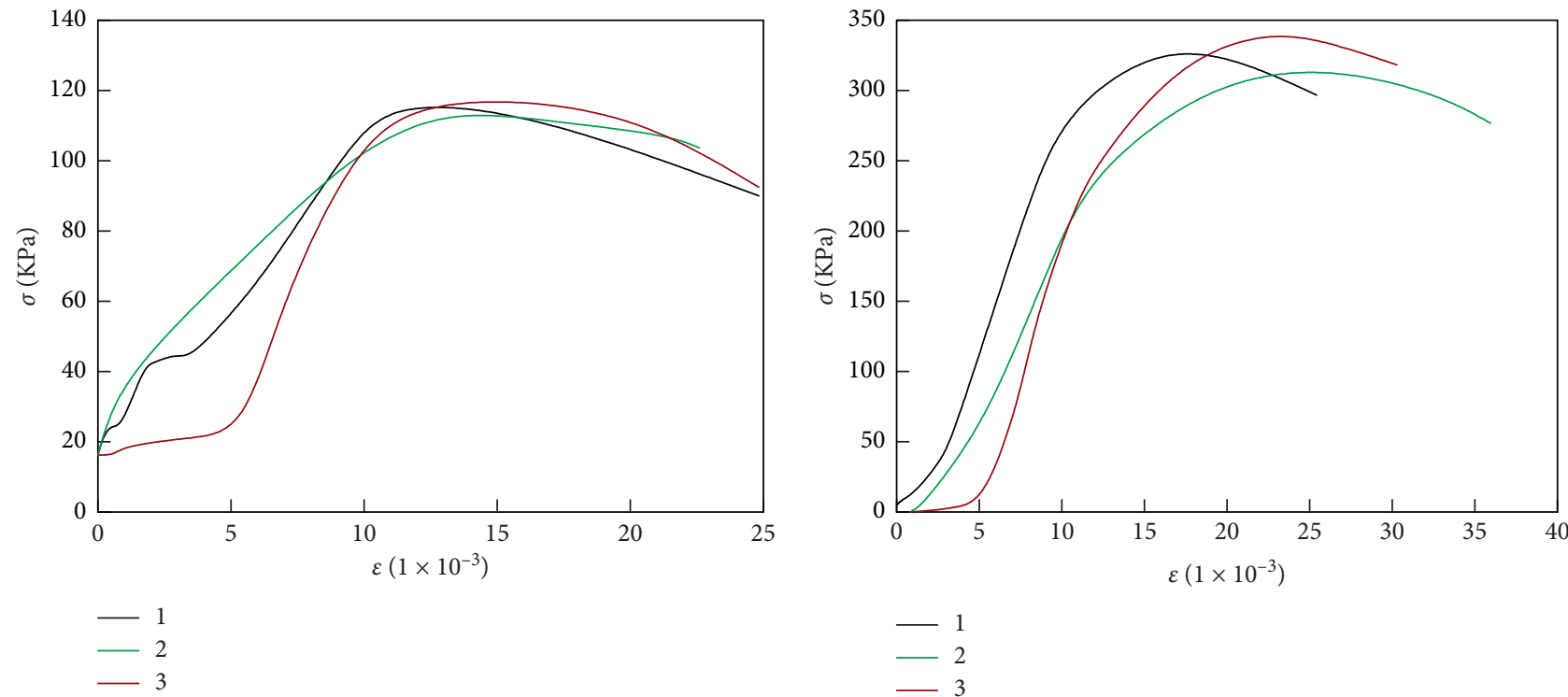

(c)

(d)

FIgURE 4: Stress-strain curves for an organic material proportion of 9\%. (a) Samples containing RH. (b) Samples containing SD. (c) Samples containing CD. (d) Samples containing RD.

compressive strength. Therefore, the best solution regarding the use of organic material is to enhance the porosity as much as possible under the condition of satisfying the mechanical property requirements. $\mathrm{Xu}$ et al. noted that the self-stability and antierosion ability of vegetation-concrete on a slope is sufficient when the unconfined compressive strength is more than $0.3 \mathrm{MPa}$ and space for plant growth is sufficient when the total porosity is between $30 \%$ and $45 \%$ [32]. According to the research results in this paper, a suitable organic material has a small grain size, and the appropriate mixing proportion is between $7 \%$ and $9 \%$. Under this condition, the unconfined compressive strength can exceed $0.34 \mathrm{MPa}$, and the total porosity can exceed $36.15 \%$.

\section{Conclusions}

With an increase in the organic material proportion, the sealed porosity of vegetation-concrete remains stable, the total porosity increases, and the unconfined compressive strength decreases. The main reason for these trends is that the connected porosity increases.

Although the total and connected porosity of samples containing organic material with a large grain size are clearly higher than those containing organic material with a small grain size, the resulting unconfined compressive strength and elasticity modulus are too low for vegetation-concrete to maintain self-stability. Therefore, organic material with a 


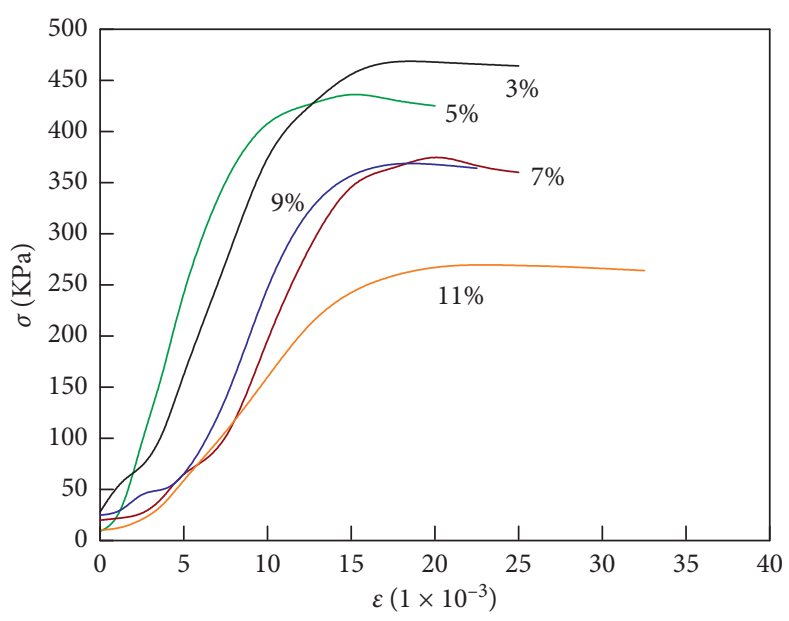

(a)

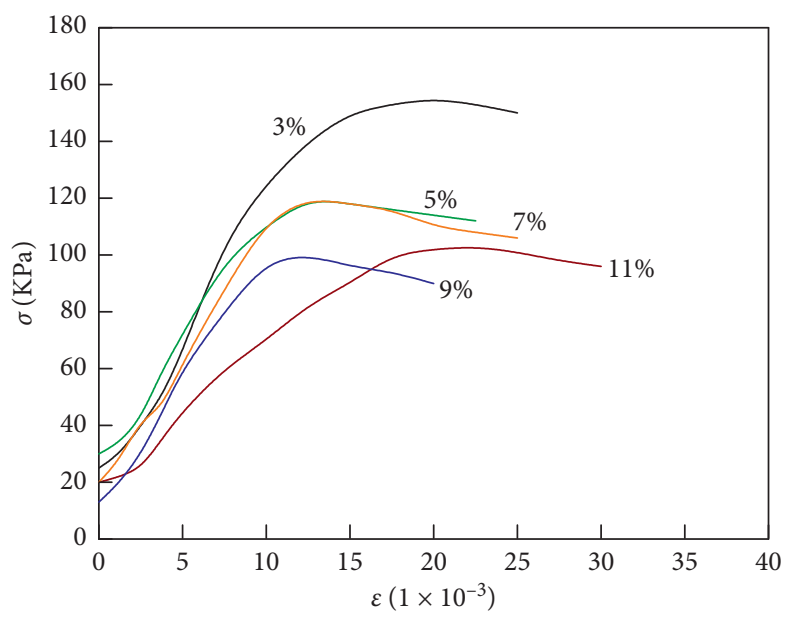

(c)

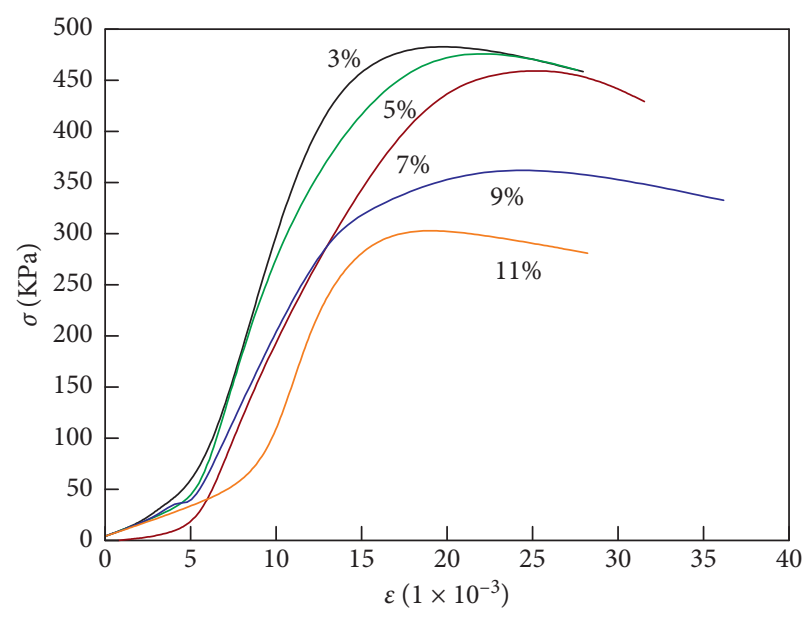

(b)

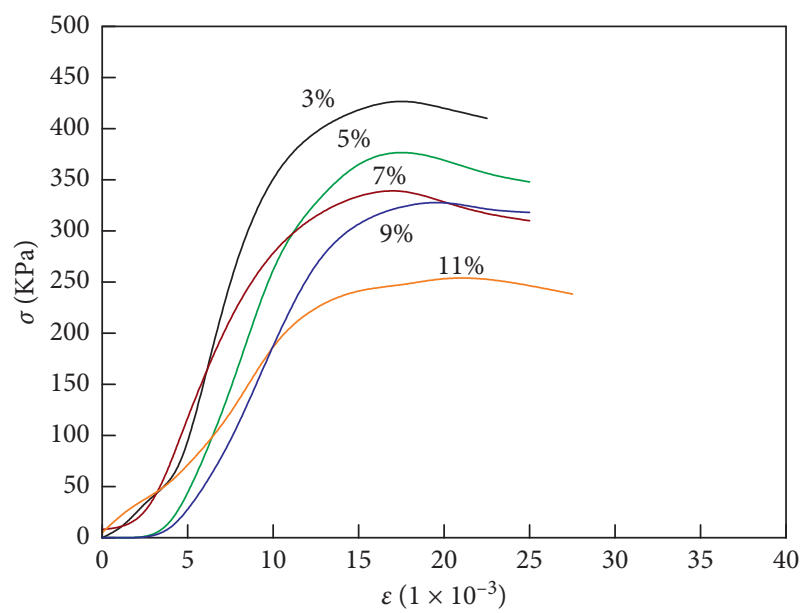

(d)

Figure 5: Stress-strain curves of all the samples. (a) Samples containing RH. (b) Samples containing SD. (c) Samples containing CD. (d) Samples containing RD.

TABLE 2: Unconfined compressive strengths of the samples (MPa).

\begin{tabular}{lccccc}
\hline \multirow{2}{*}{ Type of organic material } & \multicolumn{5}{c}{ Proportion of organic material } \\
& $3 \%$ & $5 \%$ & $7 \%$ & $9 \%$ & $11 \%$ \\
\hline $\mathrm{RH}$ & 0.468 & 0.439 & 0.378 & 0.367 & 0.269 \\
$\mathrm{SD}$ & 0.495 & 0.483 & 0.452 & 0.357 & 0.305 \\
$\mathrm{CD}$ & 0.158 & 0.126 & 0.105 & 0.097 & 0.112 \\
$\mathrm{RD}$ & 0.429 & 0.381 & 0.342 & 0.326 & 0.254 \\
\hline
\end{tabular}

TABLE 3: Elasticity moduli of the samples $(\mathrm{MPa})$.

\begin{tabular}{lccccc}
\hline \multirow{2}{*}{ Type of organic material } & \multicolumn{5}{c}{ Proportion of organic material } \\
& $3 \%$ & $5 \%$ & $7 \%$ & $9 \%$ & $11 \%$ \\
\hline RH & 50.121 & 44.863 & 41.236 & 38.449 & 22.264 \\
SD & 56.453 & 48.788 & 36.633 & 34.676 & 27.937 \\
CD & 14.894 & 11.847 & 11.089 & 9.372 & 5.962 \\
RD & 53.315 & 40.213 & 37.711 & 33.490 & 22.913 \\
\hline
\end{tabular}

large grain size is not suitable for use in vegetation-concrete directly; it needs to be crushed before being used to prevent crack formation.
Considering the requirements concerning plant growth and mechanical properties, organic materials with a small grain sizes are more suitable for use in vegetation-concrete, and the suitable mixing proportion is between $7 \%$ and $9 \%$.

\section{Data Availability}

All data in this manuscript used to support the findings of this study are available from the corresponding author upon request.

\section{Conflicts of Interest}

The authors declare that there are no conflicts of interest regarding the publication of this paper.

\section{Acknowledgments}

This study was supported by the National Key R\&D Program of China (Grant No. 2017YFC0504902-02), the National Natural Science Foundation of the People's Republic of 
China (Grant Nos. 51708333 and 51678348), the Open Fund of the Key Laboratory of Geological Hazards on Three Gorges Reservoir Area (China Three Gorges University) Ministry of Education (Grant No. 2018KDZ11), the Natural Science Foundation of Hubei Province (Grant Nos. 2016CFA085 and 2017ACA189), and the Open Fund of the Key Laboratory of Disaster Prevention and Mitigation, Hubei Province (Grant No. 2016KJZ13).

\section{References}

[1] T. Huang, C. J. Liu, J. Y. Liao, and H. Tang, "Thick layer base material spraying slope protection technique applying in Shaohuai highway," Journal of Northwest Forestry University, vol. 24, no. 6, pp. 77-79, 2009.

[2] X. M. Wang, J. P. Chen, Y. Y. Zhou, and C. Q. Zuo, “Application of plant protection of thick-layer backing in red siltstone slope," Journal of Highway and Transportation Research and Development, vol. 27, no. 2, pp. 152-158, 2010.

[3] S. Y. Xie and X. C. You, "Application of soil spraying technology with double-layer protecting mesh in slope protection," Yangtze River, vol. 46, no. 14, pp. 105-107, 2015.

[4] L. Y. Wang, X. S. Zhang, X. B. Gao, and F. S. Zhai, "The application progress of soil spraying technology for ecological protection engineering," Shanxi Architecture, vol. 41, no. 27, pp. 191-192, 2015.

[5] Y. Chen, Y. Z. Liang, D. X. Liu, and W. N. Xu, "Plant fiber reinforced effects on frost resistance durability of vegetationconcrete," Hubei Agricultural Sciences, vol. 54, no. 19, pp. 4840-4844, 2015.

[6] Y. Chen, D. X. Liu, X. Y. Yao, and W. N. Xu, "Determination of anchor parameters in vegetation-concrete ecological protection technology," Yangtze River, vol. 46, no. 21, pp. 23-26, 2015.

[7] Y. Z. Liang, Y. Chen, D. X. Liu, W. N. Xu, and X. Y. Yao, "Effect of additive plant fiber on shearing strength of vegetation-concrete under freezing-thawing cycles," Bulletin of Soil and Water Conservation, vol. 36, no. 2, pp. 136-139, 2016.

[8] J. H. Zhang, Q. R. Chang, K. L. Jia, T. Chen, Q. L. Yue, and Y. J. Li, "Effect of plant restoration to soil fertility quality on loess plateau," Journal of Soil and Water Conservation, vol. 17, no. 4, pp. 38-41, 2003.

[9] W. T. Chen, Y. M. Fu, Y. Y. Sui, X. B. Liu, and J. W. Li, "Effects of long-term fertilization on enzyme activities and soil fertility for black farmlands under different soil matter levels," Chinese Agricultural Science Bulletin, vol. 29, no. 15, pp. 78-83, 2013.

[10] N. C. Consoli, D. A. Rosa, R. C. Cruz, and A. D. Rosa, "Water content, porosity and cement content as parameters controlling strength of artificially cemented silty soil," Engineering Geology, vol. 122, no. 3-4, pp. 328-333, 2011.

[11] Y. D. Liao, C. H. Jiang, and X. G. Feng, "An empirical correlation between unconfined compression strength and curing time for cement-soil," Applied Mechanics and Materials, vol. 268-270, pp. 642-645, 2013.

[12] S. Koshikawa and Y. Itoh, "Research on watertightness evaluation of field concrete," Concrete Research and Technology, vol. 7, no. 1, pp. 31-40, 1996.

[13] J. Murata and C. E. Member, "Studies on the permeability of concrete," Transaction of Japan Society of Civil Engineers, vol. 1961, no. 77, pp. 69-103, 1961.

[14] T. Okamoto, N. Yasuda, N. Masui, and F. Sato, "Preparation, properties and test method of porous concrete," Concrete Engineering, vol. 36, no. 3, pp. 52-62, 1998.
[15] J. Yang and G. L. Jiang, "Experimental study on properties of pervious concrete pavement materials," Cement and Concrete Research, vol. 33, no. 3, pp. 381-386, 2003.

[16] Y. Wang, Q. Yuan, D. Deng, and Z. Liu, "Modeling compressive strength of cement asphalt composite based on pore size distribution," Construction and Building Materials, vol. 150, pp. 714-722, 2017.

[17] D. X. Liu, W. N. Xu, Z. L. Cheng, Z. J. Zhou, X. Y. Cai, and B. Q. Zhao, "Improvement test on frost resistance of vegetation-concrete and engineering application of test fruitage," Environmental Earth Sciences, vol. 69, no. 1, pp. 161-170, 2013.

[18] J. Yang, Building Material, China Water \& Power Press, Beijing, China, 2004.

[19] Z. Y. Xia, W. N. Xu, and L. H. Wang, "Research on characteristics of early strength of ecological slope-protected base material of vegetation- growing concrete," Rock and Soil Mechanics, vol. 32, no. 6, pp. 1719-1724, 2011.

[20] H. Xiao, J. Huang, Q. Ma et al., "Experimental study on the soil mixture to promote vegetation for slope protection and landslide prevention," Landslides, vol. 14, no. 1, pp. 287-297, 2015.

[21] Z. A. Rahman, N. Sulaiman, S. A. Rahim, W. M. R. Idris, and T. Lihan, "Effect of cement additive and curing period on some engineering properties of treated peat soil," Sains Malaysiana, vol. 45, no. 11, pp. 1679-1687, 2016.

[22] B. J. Zhang, B. Huang, X. D. Fu, and L. Xiao, "An experimental study of strength and deformation properties of cemented soil core sample and its constitutive relation," Rock and Soil Mechanics, vol. 36, no. 12, pp. 3417-3424, 2015.

[23] C. Zhao, X. D. Shen, S. H. Jia, and C. F. Zhao, "Influence of density on strength of cemented soil," Chinese Journal of Geotechnical Engineering, vol. 35, pp. 360-365, 2013.

[24] D. Ribeiro, R. Néri, and R. Cardoso, "Influence of water content in the UCS of soil-cement mixtures for different cement dosages," Procedia Engineering, vol. 143, pp. 59-66, 2016.

[25] C. A. Anagnostopoulos, "Strength properties of an epoxy resin and cement-stabilized silty clay soil," Applied Clay Science, vol. 114, pp. 517-529, 2015.

[26] A. Kumar and D. Gupta, "Behavior of cement-stabilized fiberreinforced pond ash, rice husk ash-soil mixtures," Geotextiles and Geomembranes, vol. 44, no. 3, pp. 466-474, 2016.

[27] W. G. Liang and Y. S. Zhao, "Testing study on mechanical property of Thenardite rock salt," Chinese Journal of Rock Mechanics and Engineering, vol. 23, no. 3, pp. 391-394, 2004.

[28] D. L. Meng, "The experimental research about aggregate size on concrete catastrophe damage," Doctoral Dissertation, Yanshan University, Qinhuangdao, China, 2014.

[29] Y. Zhang, Y. Wang, N. Zhao, T. Wang, and Y. Zhang, "Experimental and stress-strain equation investigation on compressive strength of raw and modified soil in loess plateau," Advances in Materials Science and Engineering, vol. 2016, Article ID 2681038, 10 pages, 2016.

[30] B. F. Zheng, J. Y. Zhang, and S. C. Li, "Study on basic features of thick layer base material," Subgrade Engineering, vol. 3, pp. 1-4, 2001.

[31] D. P. Zhou and J. Y. Zhang, Vegetation Protection Engineering, China Communications Press, Beijing, China, 2003.

[32] Y. Xu, F. Q. Chen, Z. L. Jin, L. P. Wan, D. Xia, and G. P. Liu, "Analysis on variation in alternate years of base material soil fertility for vegetation concrete eco-slope protection of hydropower station," Water Resources and Hydropower Engineering, vol. 43, no. 11, pp. 47-50, 2012. 


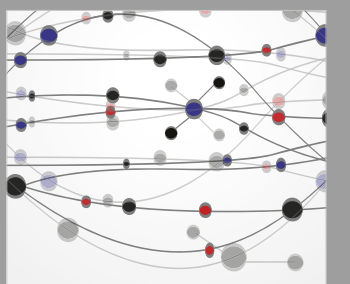

The Scientific World Journal
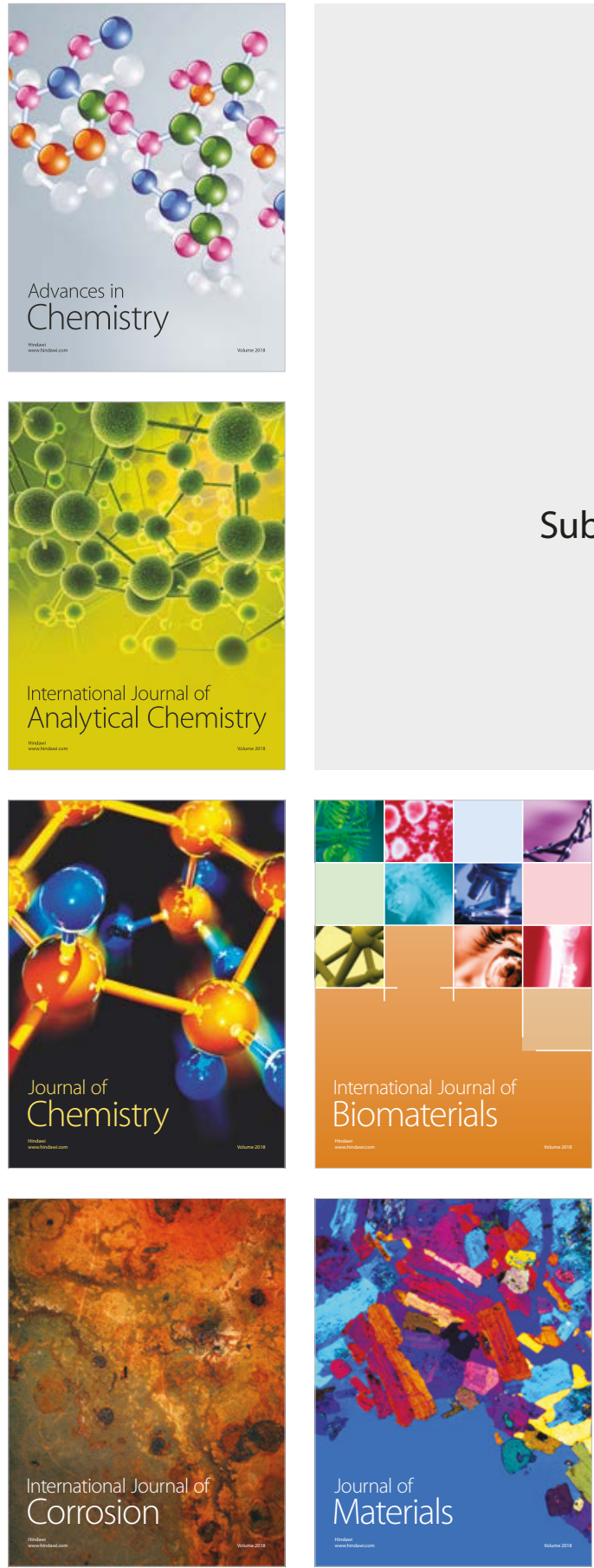

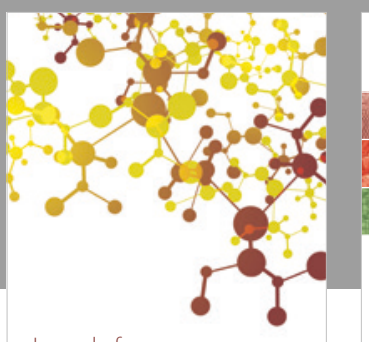

Journal of

Applied Chemistry
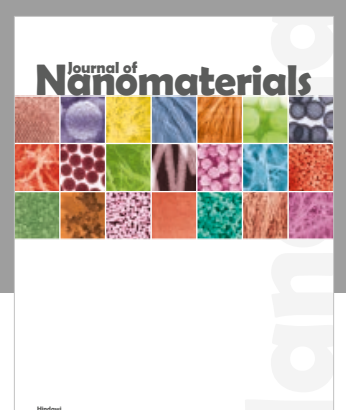

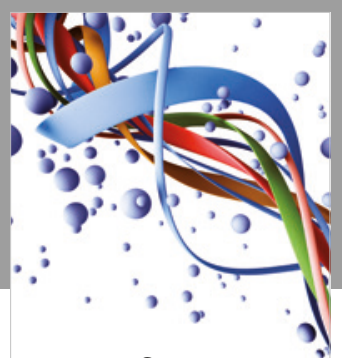

Scientifica

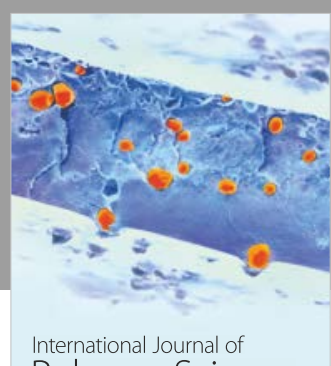

Polymer Science

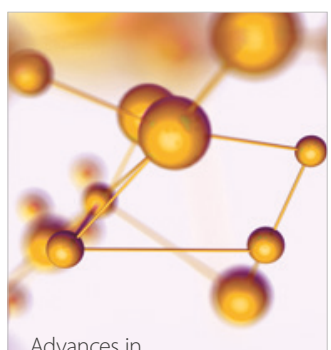

Physical Chemistry
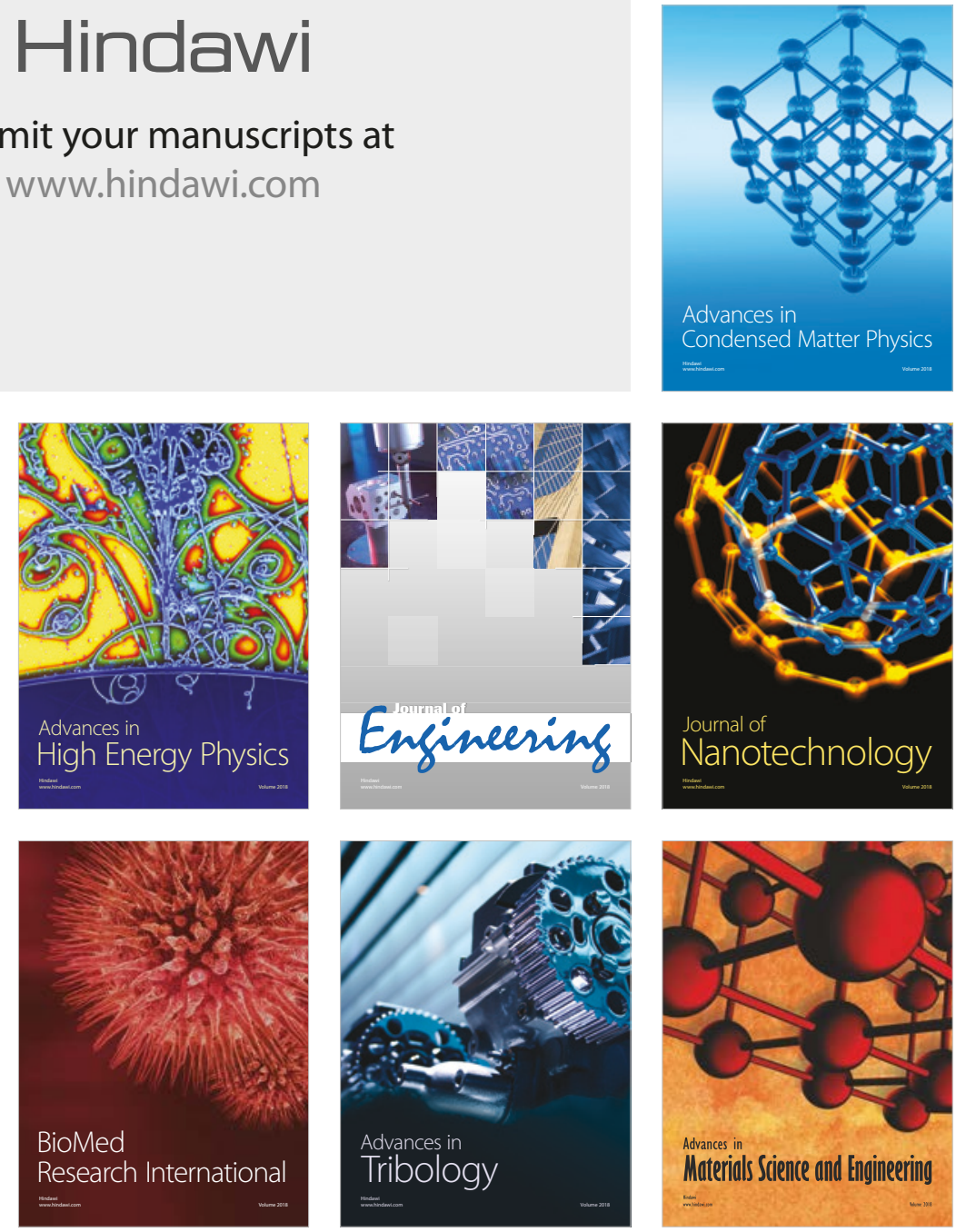